\title{
Exploring Pre-Service Teachers' Emotional Competence and Motivation for the Choice of a Teaching Career
}

\author{
Tea Pavin Ivanec \\ Faculty of Teacher Education, University of Zagreb, Zagreb, Croatia \\ https:// orcid.org/0000-0003-3225-2272
}

\begin{abstract}
The literature recognises the importance of teachers' emotional competence for various aspects of the teaching profession, as well as the importance of attracting motivated and quality prospective teachers and retaining them in the profession. However, studies relating to the motivation to teach and some personal characteristics of prospective teachers are still relatively scarce. Therefore, this study aimed at contributing to this field of research by exploring the association between prospective teachers' emotional competence and their motivation for the choice of a teaching career as proposed by the Factors Influencing Teaching (FIT)-Choice model. This study used a quantitative methodological approach. Prospective teachers who were enrolled in a primary school initial teacher education programme $(N=423)$ participated in this study. The data were analysed using cluster analysis and multivariate analysis of variance. The results obtained revealed that the importance of almost all motives for the decision to pursue a teaching career, and the perception of demandingness of the teaching profession are rated higher by pre-service teachers with higher emotional competence. Finally, pre-service teachers with higher emotional competence also expressed a higher level of satisfaction with their career choice compared to those with a moderate level of emotional competence.
\end{abstract}

Keywords: emotional competence; Factors influencing teaching choice (FIT) model; motivation for teaching; pre-service teachers

\section{Introduction}

In the past two decades, motivation for the choice of the teaching profession has become a prominent field of interest with an increasing number of both quantitative and qualitative studies exploring this construct in relation to various factors and contexts. Increased interest in the motivation for teaching is a result of changes in many countries worldwide which are facing a teacher shortage, an ageing teacher population, a decrease in the status of the teaching profession and the issue of attracting young people to pursue a teaching career 
(Han \& Yin; 2016; La Velle, 2019). Hence, recruiting and retaining qualified teachers has become an important issue in many countries (La Velle, 2019; Suryani, Watt \& Richardson, 2016). Teacher motivation is also related to the quality of teaching practice, student educational outcomes and teacher psychological wellbeing (Han \& Yin, 2016; Skaalvik \& Skaalvik, 2018), which is especially important in the light of continuous changes and challenges that teachers nowadays face.

Motivation for the choice of the teaching profession is important, not only for researchers, but for educational policy makers as well. A better understanding of motives for choosing the teaching profession can have significant practical implications regarding the retention and attraction of quality teachers. Bearing in mind the trend of a constant decline in the status of the teaching profession, it seems more important than ever to explore what motivates young people to pursue a teaching career, and which characteristics those highly motivated for this profession possess. Therefore, it is not surprising that the researchers (and policy makers as well) have recognised the importance of teachers' motivation within the broader construct of a teacher's professional identity (Heinz, 2015).

Accordingly, the studies exploring the motivation for the choice of teaching career have become more prominent. The general research orientation of these studies is driven by specific motivational theoretical frameworks such as expectancy-value theory or achievement goal theory. Studies exploring prospective teachers' motivation for entering the teaching profession usually classify these motives as intrinsic, altruistic and extrinsic motivation (Han \& Yin, 2016), or as intrinsic, extrinsic and social motivation (Lauermann, Karabenick, Carpenter \& Kuusinen, 2017). Extrinsic motives include motives such as a stable income and a secure job position, intrinsic motives reflect an interest in teaching, while altruistic and social motives capture the desire to work with children and adolescents and contribute to society.

More recently, the literature on the motivation for teaching also emphasises the importance of various non-academic characteristics in recruiting prospective teachers. These include motivational antecedents such as personality, interpersonal skills and communication skills (Watt, Richardson, \& Smith, 2017). Furthermore, current studies on the motivation to teach revealed some of the characteristics associated with prospective teachers' motivation, such as the chosen path of initial teacher education (pre-school, primary, secondary education) and subject/discipline-domain (e.g. STEM, non-STEM). These studies provided a worthwhile insight into the motivation for teaching and implied the need for further exploration of this complex construct. An additional impetus for exploring the motivation to teach was a FIT (Factors Influencing Teaching)Choice model (and accompanying measurement tool) proposed by Watt and Richardson (2007). This enables a more systematic comparison of findings across different educational contexts.

However, further studies are needed to explore other non-academic factors that could also be relevant for the motivation for choosing the teaching profession. 
This study focuses on one of these factors, more specifically on prospective teachers' emotional competence - a construct that can affect the quality of teachers' work, job satisfaction and professional burnout (Brackett, Palomera, Mojsa-Kaja, Reyes, \& Salovey, 2010), and consequently, it can influence teachers' intentions to remain in the profession. According to the literature, emotional competence is considered essential for the teaching profession (Vignjević Korotaj \& Mrnjaus, 2020), and crucial for successful everyday interactions with pupils (Aldrup, Carstensen, Köller, \& Klusmann, 2020). Hence, it is reasonable to assume that prospective teachers' emotional competence can be related to their motivation to pursue the teaching profession. In the following sections, a brief overview of this construct from the perspective of the teaching profession will be provided, preceded by an overview of the FIT-Choice theoretical framework which guided this study in exploring motivation to choose a teaching career.

\subsection{FIT- Choice Model of Motivation for the Choice of Teaching Profession}

Despite growing interest in the motivation to teach, a certain lack of methodological and theoretical consistencies often poses a difficulty in comparing findings of different studies, as noticed by Heinz (2015). The FIT (Factors Influencing Teaching)-Choice model by Watt and Richardson (2007) attempts to address these shortcomings, offering a broad theoretical framework for exploring motivation for the teaching profession based upon expectancyvalue theory (Eccles, 2005). Different values and expectancies of success were adapted within this model to answer what motivates individuals to pursue a teaching career and to provide the opportunity for systematic research of this particular topic (Watt \& Richardson, 2012; Watt et al., 2017). According to Watt and Richardson (2007), motivational factors assumed to be relevant for the decision to choose to teach and contained in this model are the intrinsic value of teaching (interest and enjoyment in teaching), the social utility value of teaching (including working with children/adolescents, shaping their future, making a social contribution and enhancing social equity), the personal utility value of teaching (referring to job security, time for family, and job transferability), the perception of own ability to teach, positive prior teaching and learning experiences, social influences by significant others, as well as the motive of choosing teaching as a fallback career. Further, the FIT-Choice model also includes perceptions of the teaching profession in terms of task demand (required expertise and difficulty) and task return (salary and social status). Lastly, satisfaction with career choice and experienced social dissuasion regarding this specific career choice are also a part of this model.

Previous studies conducted within the FIT-Choice model consistently indicate that the intrinsic value of teaching, the social utility value of teaching and the perception of one's own teaching abilities are among the most important motives for the choice of a teaching career, while the fallback career motive is regarded as least important in different countries and contexts (Flores \& Niklasson, 2014; Lin, Shi, Wang, Zhang, \& Hui, 2012; Richardson \& Watt, 2006; Wyatt-Smith et al., 2017). Furthermore, some studies exploring motivation for teaching among different categories of prospective teachers (enrolled in different initial teacher education programmes) revealed certain differences concerning 
social utility and the intrinsic value of teaching, as well as fallback career motive (Watt, Richardson, \& Devos, 2012; Watt, Richardson, \& Morris, 2017; WyattSmith et al., 2017), while other studies did not indicate these differences (Akar, 2012; Glutsch \& König, 2019). On the other hand, studies exploring personal characteristics (as antecedents) and motivation for choosing the teaching profession are somewhat less represented than those focused on different categories of prospective teachers.

Several studies explored the relationship between personality and motivation for teaching. For example, Jugović, Marušić, Pavin Ivanec and Vizek Vidović (2012) found that higher levels of agreeableness were related to higher intrinsic career value and the social utility value motive of prospective teachers. Intrinsic career value was also positively predicted by extraversion, and both extraversion and agreeableness were positive predictors of prospective teachers' satisfaction with their career choice. In their second study, Marušić, Jugović and Pavin Ivanec (2017) found that motivation for teaching and personality are also related to prospective teachers' achievement goals. In a study conducted by Tomšik and Gatial (2018), personality traits predicted prospective teachers' fallback career motive, whereby neuroticism was a positive predictor, and other personality traits were negative predictors of this specific motive.

Studies generally indicate that personality traits are also related to in-service teachers' effectiveness and burnout (Kim, Jörg \& Klassen, 2019), implying the importance of further research of non-academic characteristic as antecedents of the motivation for choosing a career in teaching. Considering that personality traits also include certain aspects of emotional functioning and that various measures of emotional competence significantly correlate with personality traits (Aldrup et al., 2020), it seems reasonable to assume that the constructs related to emotional functioning could also be associated with the motivation for choosing a teaching career. Besides results implying the importance of personality in explaining the motivation for teaching, studies also revealed its association with teachers' professional development, vocational motivation and career development in general (McKay \& Tokar, 2012; McLarnon, Carswell \& Schneider, 2015). Some studies also demonstrated that emotional competence is predictive of job satisfaction, even when the effects of personality traits are controlled (Urquijo, Extremera \& Azanza, 2019). Drawing upon the results of these studies, exploring the relationship of the motivation to teach and different personality-related characteristics of pre-service teachers could provide additional insight into the motivation for the choice of a teaching career.

\subsection{Teachers' Emotional Competence}

Emotional competence is a component of a broader construct of emotional intelligence (Salovey \& Meyer, 1990). In the literature it is also often explored under the construct of emotional or socioemotional competence, whereby the term 'competence' implies skills that can be acquired (Mayer \& Salovey, 1997). However, regardless of the broader theoretical framework, awareness of one's own emotions, other people's emotions, and the regulation and management of emotions appear to be crucial for coping with social and emotional situations 
successfully, including the complex demands of the teaching profession (Aldrup et al., 2020). These demands include providing support to pupils, negotiating, resolving conflict, and setting boundaries, and these interactions require emotionally competent behaviour. Additionally, emotional competence enables teachers to be more successful in encouraging and motivating pupils to engage in learning and school activities (Havik \& Westergård, 2019). These personal characteristics referring to emotional functioning can also be related to the social type of vocational interests, which include the desire to work with others (McLarnon et al., 2015).

Previous studies indicate that emotional competence plays a significant role in social skills' development; however, it can also be a determinant of academic and cognitive outcomes from childhood onwards. Interaction of teachers and pupils' emotional regulation affects school performance, and teachers are also a relevant factor in the socialisation of pupils' emotional competence (Garner, 2010). Thus, the importance of teachers' emotional competence is two-fold: on the one hand, it enables teachers to establish and maintain quality relationships with pupils (and parents and colleagues), while on the other hand, an emotionally competent teacher can be a role model of emotionally competent behaviour. Studies that linked teachers' emotional competence with some aspects of the teaching job also demonstrated the importance of emotional competence. More specifically, teachers' emotional competence substantially influences healthy teacher-pupil relationships. It reflects not only in the quality of teacher-pupil relationships, which consequently affect pupils' engagement in the classroom (Havik \& Westergård, 2019; O'Connor \& McCartney, 2007), but also in teachers' perception of job self-efficacy and wellbeing (Vesely, Saklofske \& Leschied, 2013), and in their level of job satisfaction (Anari, 2012; Platsidou, 2010). Consequently, lack of job satisfaction combined with burnout can lead to low motivation of teachers, which additionally implies the importance of emotional competence for coping with the professional requirements and challenges of the teaching profession.

The literature suggests that more effective functioning in a school environment is expected of teachers with higher levels of emotional competence since they are more likely to regulate emotions better (elicit pleasant emotions or downregulate unpleasant ones). The ability to regulate emotions is related to perceived self-efficacy and prevention of emotional exhaustion, while MéridaLópez and Extremera (2017) reported that the association of emotional intelligence and job performance is more robust in the case of more emotionally demanding professions. Respectively, the association of teachers' emotional competence with better adjustment to different demands of their job implies the importance of emotional competence for teacher motivation. Moreover, the literature also suggests that emotional competence can increase in adulthood by using interventions aimed at its enhancement (Kotsou, Nelis, Grégoire \& Mikolajczak, 2011). This also applies to teachers (Madalinska-Michalak, 2015). These findings can have practical implications for teacher development and education, both on initial and in-service teacher education levels. 
Previously described studies generally emphasise the importance of emotional competence for various aspects of the teaching profession, including effective teaching. However, the literature review implies a lack of studies exploring preservice teachers' emotional competence, especially concerning their motivation for choosing this profession, both within the FIT-Choice model and in general. In line with some previous studies on teacher motivation and its antecedents, it seems reasonable to assume that emotional competence, among other personal correlates, can also be related to the motivation for choosing a teaching career.

Hence, this study aimed at contributing to a better understanding of the motivation for teaching by relating these two constructs. This study is partly explorative, drawing upon previous findings on personal correlates of motivation for teaching that imply prospective teachers' tendency to work with others in intrinsically motivating professions. However, it is generally hypothesised that prospective teachers with a higher level of emotional competence would have higher ratings of the importance of the intrinsic and social utility value of teaching. Further, it is assumed that prospective teachers' perception of their own teaching abilities would be more salient for the choice of the teaching profession among participants with a higher level of emotional competence and that they would be more satisfied with their choice to pursue a career in teaching.

\section{Method}

This study used a quantitative methodological approach. The data were analysed by multivariate analysis by means of the Statistical Package for Social Sciences software (IBM SPSS, version 23). Research hypotheses were tested using cluster analysis and multivariate analysis of variance.

\subsection{Sample and Procedure}

Participants in this study were 423 prospective teachers -- students of an initial primary teacher education programme at the University of Zagreb, Croatia, and the sample was convenient. Initial primary teacher education in Croatia is a fiveyear university programme, and students from all years took part in the study. Participants' average age was $M=20.93(S D=1.814)$, and their participation was voluntary and anonymous, and following prescribed ethical standards. Since a large majority of initial primary teacher education students at the University of Zagreb are females (about 96\%), information on participants' gender was not collected to grant additional anonymity to male students. A questionnaire was administered during one of the regular classes by means of a paper/pencil technique upon obtaining participants' consent.

\subsection{Instruments}

The FIT-Choice scale (Watt \& Richardson, 2007) was used to assess participants' motivation for the choice of a teaching career. The scale was validated in various countries (Watt \& Richardson, 2012) and demonstrated good replicability and validity, including Croatian validation of the scale (for more details on validation and full version of the scale see Jugović, Marušić, Pavin Ivanec \& Vizek Vidović, 2012). The Motivation for the choice of teaching is a part of the FIT- 
Choice Scale consisting of 34 items and measuring the importance of different motivational factors for the decision to choose a teaching career - intrinsic value, social utility value and personal utility value of teaching, perception of own teaching abilities, prior teaching and learning experiences, social influences by others, and fallback career motive. Participants rated each motive's importance for their career choice on a seven-point scale ranging from 1 (not at all important) to 7 (extremely important). The Perceptions of teaching profession part of the scale (12 items) includes the perception of demands (in terms of required expertise and demandingness); and returns (in terms of salary and social status) of the teaching profession. The FIT-Choice scale also comprises additional subscales referring to satisfaction with career choice (2 items) and social dissuasion experience regarding that choice ( 3 items). For this part of the scale, participants expressed their agreement level with each item on a rating scale from 1 (not at all) to 7 (extremely). Results on each subscale were calculated as an average of associated items, and reliabilities of most subscales (calculated as Cronbach's alpha coefficients) have demonstrated to be very good (Table 1).

Emotional competence was assessed by the Emotional Skills and Competence Questionnaire (ESCQ-45, Takšić, 2002) based on Mayer and Salovey's model and previously validated in several international studies (for more details and the questionnaire see Faria et al., 2006). This questionnaire is a 45-item instrument consisting of three subscales: the ability to perceive and understand emotions (15 items), the ability to express and label emotions (14 items), and the ability to manage and regulate emotions (16 items). Participants assessed the level to which each item refers to them from 1 (not at all) to 5 (completely). Results on each subscale were calculated as an average of associated items, and all subscale reliabilities are very good and $\geq .81$ (Table 1 ).

\section{Results and Discussion}

To obtain general insight into factors influencing participants' motivation for choosing the teaching profession and their emotional competence, descriptive statistics and subscale reliabilities for all measured variables are calculated on a total sample $(N=423)$ and their values are displayed in Table 1.

Table 1: Reliabilities, means and standard deviations for the FIT-Choice factors and emotional competence factors

\begin{tabular}{lccc}
\hline FIT-Choice: Motivations & $\mathrm{a}$ & $M$ & $S D$ \\
\cline { 2 - 4 } Intrinsic career value & .81 & 6.02 & 0.976 \\
Social utility value & .91 & 5.86 & 0.871 \\
Ability & .79 & 5.63 & 0.942 \\
Prior teaching and learning experiences & .80 & 4.88 & 1.579 \\
Personal utility value & .78 & 4.53 & 1.080 \\
Social influences & .88 & 4.63 & 1.818 \\
Fallback career & .62 & 2.21 & 1.345 \\
\hline FIT-Choice: Perceptions & & & \\
Task demand & .81 & 5.56 & 0.860 \\
Task return & .84 & 3.23 & 0.998 \\
\hline
\end{tabular}




\begin{tabular}{llll}
\hline FIT-Choice: Choice of teaching career & & & \\
$\quad$ Satisfaction with choice & .85 & 6.11 & 1.100 \\
$\quad$ Social dissuasion & .81 & 3.64 & 1.710 \\
\hline $\begin{array}{l}\text { Emotional competence } \\
\quad \begin{array}{l}\text { Ability to perceive and understand } \\
\text { emotions }\end{array}\end{array}$ & .92 & 3.88 & 0.596 \\
$\begin{array}{l}\text { Ability to express and label emotions } \\
\quad \begin{array}{l}\text { Ability to manage and regulate } \\
\text { emotions }\end{array}\end{array}$ & .91 & 3.69 & 0.682 \\
& .81 & 3.93 & 0.463 \\
\hline
\end{tabular}

Based on the results displayed in Table 1, it can be generally concluded that prospective classroom teachers are mostly motivated by the intrinsic career value, the social utility value and their perceptions of their own teaching abilities. These results reflect prospective teachers' desire to work with others in an intrinsically motivating profession which corresponds to their self-perceived abilities. Although ratings of the importance of prior teaching and learning experiences, the personal utility value of teaching and social influences are lower compared to the first three motives, their ratings are also above the theoretical scale average. This implies that these motives were to a certain extent important for participants' decision to become teachers. The fallback career motive was the only motive rated below the theoretical scale average, implying that participants in this study were not motivated to choose a teaching career because they failed to (or did not) pursue their first-choice career.

These results are in line with previous studies on motivation for the choice of teaching, as well as results indicating that prospective teachers perceive that their chosen profession is relatively high in demands and low in returns (concerning social status and salary) (Nesje, Brandmo, \& Berger, 2017; Richardson \& Watt, 2006; Wyatt-Smith et al., 2017). The average results on emotional competence factors also shifted towards higher values, which is not surprising considering that these participants chose a profession which includes working with others. Previous studies indicated an association between personality (which also includes emotional functioning) and social vocational interests and choices (Berings, De Fruyt, \& Bouwen, 2004). Similar results regarding relatively high self-ratings of emotional competence were also obtained on a sample of in-service teachers in a recent study conducted by Vignjević Korotaj and Mrnjaus (2020). They also pointed out that these high ratings could partly reflect the respondents' need to comply with the expected professional role of teachers.

To compare results on FIT-Choice factors with regard to participants' emotional competence, the first step in the analysis was a cluster analysis. More specifically, participants' self-ratings of their emotional competence served as a basis for $k$-means cluster analysis, resulting in two clusters which differ on all three emotional competence subscales. Mean cluster-values are displayed in Figure 1 (differences between cluster centres were all statistically significant at $p<.01)$. According to mean values, the first cluster $(\mathrm{Q} 1 ; n=225)$ is characterised by somewhat lower (but not low) ratings, while the second cluster (Q2; $n=198)$ is 
characterised by rather high ratings on all subscales of emotional competence. Hence, based on the mean values, the first cluster can be labelled as a moderate emotional competence, and the second cluster can be labelled as a high emotional competence.

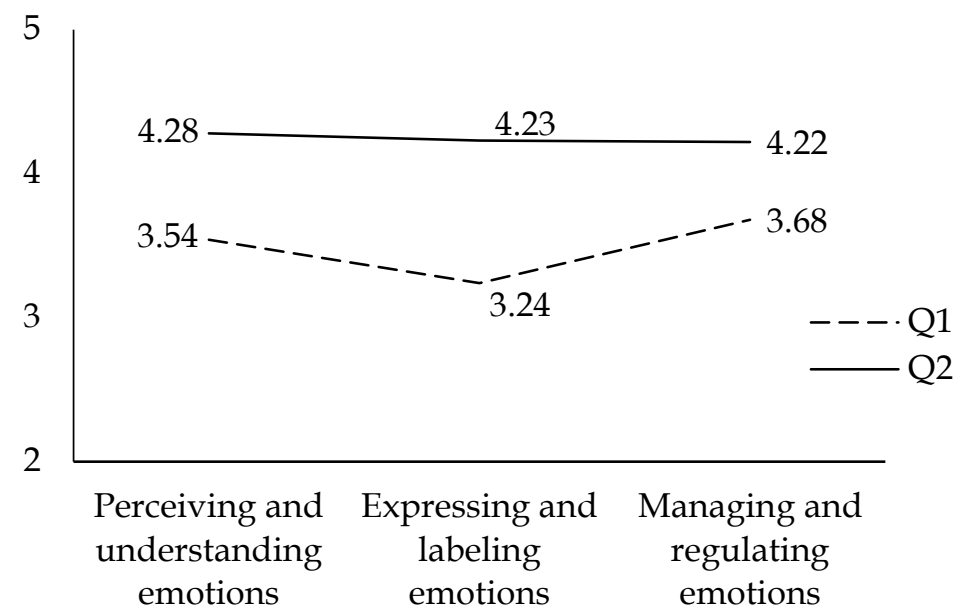

Figure 1: Final cluster centres for the two groups of participants (Note: $\mathrm{Q} 1$ = moderate emotional competence; $\mathrm{Q} 2$ = high emotional competence)

Differences in the importance of proposed motives for the choice of teaching, perception of the profession and satisfaction with this choice between the two groups (based on the cluster membership) were explored by multivariate analysis of variance. Results revealed a significant difference between the two groups and a large effect size of group membership $(F(1,349)=5.21 ; p<.001$; partial $\left.\eta^{2}=.145\right)$. Further comparisons between the groups on each FIT-Choice factor are displayed in Table 2.

Table 2: Results of the MANOVA for the FIT-Choice factors with regard to the cluster membership

\begin{tabular}{lcccccc}
\hline & \multicolumn{9}{c}{$\mathrm{Q} 1$} & \multicolumn{2}{c}{$\mathrm{Q} 2$} & \\
\cline { 2 - 5 } Motivations & $M$ & $S D$ & $M$ & $S D$ & $F$ & $\eta_{\mathrm{p}}{ }^{2}$ \\
\hline Intrinsic career value & 5.88 & 0.999 & 6.22 & 0.911 & $10.87^{* *}$ & .030 \\
Social utility value & 5.64 & 0.858 & 6.08 & 0.832 & $24.04^{* *}$ & .064 \\
$\quad$ Personal utility value & 4.28 & 1.046 & 4.81 & 1.069 & $46.05^{* *}$ & .117 \\
Ability & 5.38 & 0.897 & 6.00 & 0.816 & $7.51^{* *}$ & .021 \\
$\quad$ Social influences & 4.35 & 1.769 & 4.92 & 1.808 & $21.99^{* *}$ & .059 \\
$\quad$ Prior teaching and learning & 4.63 & 1.546 & 5.09 & 1.576 & $8.77^{* *}$ & .025 \\
$\quad$ experiences & & & & & & \\
$\quad$ Fallback career & 2.33 & 1.343 & 2.08 & 1.383 & 2.75 & .008 \\
\hline Perceptions & & & & & & \\
$\quad$ Task demand & 5.49 & 0.829 & 5.69 & 0.873 & $4.90^{*}$ & .014 \\
$\quad$ Task return & 3.21 & 1.004 & 3.26 & 0.967 & 0,24 & .001 \\
\hline Choice of teaching career & & & & & & \\
$\quad$ Satisfaction with choice & 5.96 & 1.113 & 6.28 & 1.076 & $7.58^{* *}$ & .021 \\
$\quad$ Social dissuasion & 3.55 & 1.667 & 3.62 & 1.702 & 0.12 & .001 \\
\hline
\end{tabular}

Note. ${ }^{* *}=p<.01 ;{ }^{*}=p<.05$. 
As results presented in Table 2 reveal, a significant effect of cluster membership was obtained for most of the FIT-Choice factors, whereby group-ratings were similar only for the fallback career motive, the perception of the returns of the teaching profession and the level of experienced social dissuasion regarding the choice of this career. The groups' average results indicate that the trend of obtained differences between the groups is the same - participants who perceive themselves as more emotionally competent have higher ratings of all FIT-Choice motivational factors. In addition, they perceive teaching as more demanding, and they also express a higher level of satisfaction with their career choice than participants with a moderate level of emotional competence.

The results obtained confirmed some of the initial assumptions. As hypothesised, results demonstrated more pronounced motives of intrinsic career value and social utility value of teaching among prospective teachers with a higher level of emotional competence. As already mentioned, there is a lack of studies relating these two constructs; however, this finding can be explained in relation to some previous studies exploring (prospective) teachers' personality (which also includes emotional functioning) and vocational interests in general. Jugović et al. (2012) found that these two motives correlate with personality traits, and personality traits also correlate with emotional competence (Aldrup et al., 2020; Alegre, Pérez-Escoda, \& López-Cassá, 2019). Further, individuals who are more prone to positive emotionality, and who are warm and attentive in relation to others are more likely to express the social type of vocational interest (McLarnon et al., 2015).

Hence, conclusions drawn from these studies could explain the results obtained in this study. More specifically, the importance of the social utility value of teaching, which includes working with others (in this case, children) is expected to be more pronounced among participants who have a higher level of emotional competence. From this perspective, higher intrinsic motivation is also meaningfully related to emotional competence, considering that it is not surprising that individuals who perceive themselves as better in emotionseliciting interpersonal situations are more likely to be intrinsically motivated to choose a profession in which these situations are common and expected.

Results regarding the importance of the perception of one's own teaching abilities also support the previous assumption regarding the choice of the profession that corresponds to perceived abilities. Perception of one's own teaching abilities is one of the highly important motives for the choice of the teaching profession among this study's participants. Furthermore, ratings of this motive's importance are significantly higher among participants with a high level of emotional competence, which is in line with postulated assumptions, and implies that emotional competence is also a significant (non-academic) characteristic of quality (prospective) teachers. More specifically, if participants' perceptions of own abilities to teach are an important motivational factor, it could mean that their self-perception of some other characteristics, in this case, emotional competence, could also have a significant role in motivation for this profession. Teacher-pupils interaction includes numerous situations and 
challenges in which the ability to recognise one's own and the emotions of others, as well as emotional regulation are required. It is reasonable to assume that those individuals who perceive themselves as more competent in different emotion-eliciting situations would feel more able to cope with these challenges and meet the demands of the teaching profession which include such situations on an everyday basis. Consequently, the decision to pursue a specific career, in this case teaching, is related to individuals' expectations of success which are higher if a person perceives that she/he is able to meet the requirements of the profession (Eccles, 2005). In addition, higher levels of commitment to the choice of teaching are expected from individuals who perceive themselves as more efficacious in teaching (Lauermann et al., 2017).

Other than previously addressed results regarding some initial assumptions, this study also revealed that prospective teachers with a high level of emotional competence rate the importance of personal utility value of teaching, social influences and prior positive teaching experiences more highly compared to prospective teachers with a moderate level of emotional competence. It is possible that participants with higher emotional competence, in accordance with their self-perceived characteristics, view the teaching profession as a generally more valuable choice in terms of different motives that could attract them to this profession. Hence, they perceive most of the motives as overall more important. In other words, the congruence of self-perceived characteristic (emotional, teaching) and the demands of the teaching profession could result in higher levels of importance of different motives which could attract individuals to consider teaching as their career choice. Additionally, higher levels of the importance of social influences could imply that participants' high level of emotional competence is also recognised by significant others who perceive them as highly suitable for a teaching career and who think that they should become teachers. The results obtained also indicated that participants with a higher level of emotional competence also perceived teaching as more demanding in terms of the required expertise, expected workload and emotional demands, which could also imply congruence between self-perceived abilities and requirements of the profession.

Finally, this study's results also revealed that participants with higher levels of emotional competence express higher degrees of satisfaction with the chosen educational path, which is in line with the initial assumptions. These results can be related to those obtained by Farnia, Nafukho, and Petrides (2018) which indicate that individuals with higher emotional intelligence are more effective in career-decision-making owing to more effective coping strategies with challenging situations in life in general (with career-choice being one of them). On the other hand, those with lower emotional intelligence are somewhat more prone to career indecisiveness which can reflect on satisfaction with the choice. Prospective teachers who are more satisfied with their career choice are probably more likely to be committed to complete initial teacher education, and be more satisfied upon entering the profession, which can further be reflected in their engagement in the profession (Burić \& Macuka, 2018). 


\section{Conclusion}

As hypothesised, both the intrinsic and social utility value of teaching are more pronounced among prospective teachers with a higher level of emotional competence. Additionally, the perceived ability to teach, as a motivational factor, is also more salient for this group of prospective teachers, and they are more satisfied with their career choice. This study revealed some meaningful associations between emotional competence and motivation for the teaching profession, and in spite of the lack of literature on this specific association, certain parallels are drawn with some previous studies in the field of teacher motivation, personality and career choices.

The ability to recognise one's own and the emotions of others, as well as emotional regulation, is necessary to cope with everyday challenges arising from complex teacher-pupil interactions. Therefore, it is not surprising that individuals who perceive themselves as more emotionally competent are more likely to be intrinsically motivated for a profession that requires such abilities and includes working with others. However, certain limitations of this study should also be considered when inferring conclusions. Firstly, participants in this study are prospective teachers enrolled in an initial primary teacher education programme. Hence, to obtain additional insight into the relationship of emotional competence and motivation for teaching, more heterogeneous samples of prospective teachers (in terms of initial teacher education programmes for different educational levels and domains) should also be included in future studies. Furthermore, results are based on participants' selfratings, which evoke the question of socially desirable answers, especially considering relatively high ratings on most measured variables. Finally, it would also be useful to explore further the relative contribution of emotional competence combined with personality traits.

The results of this study, as well as further exploration of antecedents related to motivation to teach, could also have practical implications for career counselling, and both initial and in-service teacher education, especially bearing in mind that emotional competence can be enhanced through planned educational interventions. These interventions (either on initial or in-service level) could additionally prepare teachers to respond appropriately to specific social and emotional demands of the profession. Initial teacher education should also consider potentially different motivational profiles among individuals who chose to pursue this career path. According to Richardson and Watt (2015), different types of motivational profiles can respond differently to specific school contexts and their level of professional commitment, responsibility and teaching effectiveness can vary. Consequently, it is necessary to reconsider initial teacher education programmes in terms of matching different profiles, different interventions and support that would prepare pre-service teachers for the demands of the teaching profession. 


\section{References}

Akar, E. O. (2012). Motivation of Turkish pre-service teachers to choose teaching as a career. Australian Journal of Teacher Education, 37(10), 76-84. doi.org/10.14221/ajte.2012v37n10.7

Aldrup, K., Carstensen, B., Köller, M. M., \& Klusmann, U. (2020). Measuring teachers' social-emotional competence: Development and validation of a Situational Judgement Test. Frontiers in Psychology, 11, 892. doi.org/10.3389/fpsyg.2020.00892

Alegre, A., Pérez-Escoda, N., \& López-Cassá, E. (2019). The relationship between trait emotional intelligence and personality. Is trait EI really anchored within the Big Five, Big Two and Big One frameworks? Frontiers in Psychology, 10, 866. doi.org/10.3389/fpsyg.2019.00866

Anari, N. N. (2012). Teachers: Emotional intelligence, job satisfaction, and organizational commitment. Journal of Workplace Learning, 24(4), 256-269.

Berings, D., De Fruyt, D. D., \& Bouwen, R. (2004). Work values and personality traits as predictors of enterprising and social vocational interests. Personality and Individual Differences, 36, 349-364. doi.org/10.1016/s0191-8869(03)00101-6

Brackett, M. A., Palomera, R., Mojsa-Kaja, J., Reyes, M. R., \& Salovey, P. (2010). Emotionregulation ability, burnout, and job satisfaction among British secondary-school teachers. Psychology in the Schools, 47(4), 406-417. doi.org/10.1002/ pits.20478

Burić, I., \& Macuka, I. (2018). Self-efficacy, emotions and work engagement among teachers: A two wave cross-lagged analysis. Journal of Happiness Studies, 19, 19171933. doi.org/10.1007/s10902-017-9903-9

Eccles, J. S. (2005). Subjective task value and the Eccles et al. model of achievementrelated choices. In A. J. Elliot \& C. S. Dweck (Eds.), Handbook of competence and motivation (pp. 105-121). New York, NY: Guilford Press.

Faria, L., Lima Santos, N., Takšić, V., Räty, H., Molander, B., Holmström, S., ... Toyota, H. (2006). Cross-cultural validation of the Emotional Skills and Competence Questionnaire (ESCQ). Psicologia, 20(2), 95-127. Retrieved from: http://www.scielo.mec.pt/pdf/psi/v20n2/v20n2a05.pdf

Farnia, F., Nafukho, F. M., \& Petrides, K. V. (2018). Predicting career decision-making difficulties: The role of trait emotional intelligence, positive and negative emotions. Frontiers in Psychology, 9: 1107. doi.org/10.3389/fpsyg.2018.01107

Flores, M. A., \& Niklasson, L. (2014). Why do student teachers enrol for a teaching degree? A study of teacher recruitment in Portugal and Sweden. Journal of Education for Teaching: International Research and Pedagogy, 40(4), 328-343. doi.org/10.1080/02607476.2014.929883

Garner, P. W. (2010). Emotional competence and its influences on teaching and learning. Educational Psychology Review, 22, 297-231. doi.org/10.1007/s10648-010-9129-4

Glutsch, N., \& König. J. (2019). Preservice teachers' motivations for choosing teaching as a career: Does subject interest matter? Journal of Education for Teaching: International Research and Pedagogy, 45(3), 1-17.

Han, J., \& Yin, H. (2016). Teacher motivation: Definition, research development and implications for teachers. Cogent Education, 3: 1217819. doi.org/10.1080/2331186x.2016.1217819

Havik, T., \& Westergård, E. (2019). Do teachers matter? Students' perceptions of classroom interactions and student engagement. Scandinavian Journal of Educational Research, 64(4), 488-507. doi.org/10.1080/00313831.2019.1577754

Heinz, M. (2015). Why choose teaching? An international review of empirical studies exploring student teachers' career motivations and levels of commitment to 
teaching. Educational Research and Evaluation, 21(3), 258-297.

doi.org/10.1080/13803611.2015.1018278

Jugović, I., Marušić, I., Pavin Ivanec, T., \& Vizek Vidović, V. (2012). Motivation and personality of pre-service teachers in Croatia. Asia-Pacific Journal of Teacher Education, 40(3), 271-287. doi.org/10.1080/1359866x.2012.700044

Kim, L. E., Jörg, V., \& Klassen, R. M. (2019). A meta-analysis of the effects of teacher personality on teacher effectiveness and burnout. Educational Psychology Review, 31, 163-195. doi.org/10.1007/s10648-018-9458-2

Kotsou, I., Nelis, D., Grégoire, J., \& Mikolajczak, M. (2011). Emotional plasticity: Conditions and effects of improving emotional competence in adulthood. Journal of Applied Psychology, 96(4), 827-839. doi.org/10.1037/a0023047

Lauermann, F., Karabenick, S. A., Carpenter, R. \& Kuusinen, C. (2017). Teacher motivation and professional commitment in the United States: The role of motivations for teaching, teacher self-efficacy and sense of professional responsibility. In H. M. G. Watt, P. W. Richardson \& K. Smith (Eds.), Global perspectives on teacher motivation (pp. 322-348). Cambridge, UK: Cambridge University Press. doi.org/10.1017/9781316225202.011

La Velle, L. (2019). Motivation and provision in teacher education: Context, culture and capacity. Journal of Education for Teaching, 45(5), 491-493. doi.org/10.1080/02607476.2019.1675356

Lin, E., Shi, Q., Wang, J., Zhang, S., \& Hui, L. (2012). Initial motivation for teaching: Comparison between preservice teachers in the United States and China. AsiaPacific Journal of Teacher Education, 40(3), 227-248. doi.org/10.1080/1359866x.2012.700047

Madalinska-Michalak, J. (2015). Developing emotional competence for teaching. Croatian Journal of Education, 17(Sp. Ed. No. 2), 71-97. doi.org/10.15516/cje.v17i0.1581

Marušić, I., Jugović, I., \& Pavin Ivanec, T. (2017). How personality dimensions and motivation to teach shape the learning achievement goals of Croatian future teachers. In H. M. G. Watt, P. W. Richardson \& K. Smith (Eds.), Global perspectives on teacher motivation (pp. 217-243). Cambridge, UK: Cambridge University Press. doi.org/10.1017/9781316225202.008

Mayer, J. D., \& Salovey, P. (1997). What is emotional intelligence? In P. Salovey \& D. J. Sluyter (Eds.), Emotional development and emotional intelligence: Educational implications (pp. 3-31). New York, NY: Basic Books.

McKay, D.A., \& Tokar, D.M. (2012). The HEXACO and five-factor models of personality in relation to RIASEC vocational interests. Journal of Vocational Behavior, 81, 139149. doi.org/10.1016/j.jvb.2012.05.006

McLarnon, M. J. W., Carswell, J. J., \& Schneider, T. J. (2015). A case of mistaken identity? Latent profiles in vocational interests. Journal of Career Assessment, 23(1), 166-185. doi.org/10.1177/1069072714523251

Mérida-López, S., \& Extremera, N. (2017). Emotional intelligence and teacher burnout: A systematic review. International Journal of Educational Research, 85, 121-130. doi.org/10.1016/j.ijer.2017.07.006

Nesje, K., Brandmo, C., \& Berger, J.-L. (2017). Motivation to become teacher: A Norwegian validation of the Factors Influencing Teaching Choice Scale. Scandinavian Journal of Educational Research, 1-19. doi.org/10.1080/00313831.2017.1306804

O'Connor, R., \& McCartney, K. (2007). Examining teacher-child relationships and achievement as part of an ecological model of development. American Educational Research Journal, 44, 340-369. doi.org/10.3102/0002831207302172 
Platsidou, M. (2010). Trait emotional intelligence of Greek special education teachers in relation to burnout and job satisfaction. School Psychology International, 31(1), 6076. doi.org/10.1177/0143034309360436

Richardson, P. W., \& Watt, H. M. G. (2006). Who chooses teaching and why? Profiling characteristics and motivations across three Australian universities. Asia-Pacific Journal of Teacher Education, 34(1), 27-56. doi.org/10.1080/13598660500480290

Richardson, P. W., \& Watt, H. M. G. (2015). Current and future directions in teacher motivation research. In T. C. Urdan and S. A. Karabenick (Eds.), The decade ahead: Applications and contexts of motivation and achievement, advances in motivation achievement, 16 part B, 139-173. Bingley, UK: Emerald Group Publishing. doi.org/10.1108/s0749-7423(2010)000016b008

Salovey, P., \& Meyer, J. D. (1990). Emotional intelligence. Imagination, Cognition and Personality, 9(3), 185-211. doi.org/10.2190/dugg-p24e-52wk-6cdg

Skaalvik, E. M., \& Skaalvik, S. (2018). Job demands and job resources as predictors of teacher motivation and well-being. Social Psychology of Education, 21(5), 12511275. doi.org/10.1007/s11218-018-9464-8

Suryani, A., Watt, H. M. G., \& Richardson, P. W. (2016). Students' motivations to become teachers: FIT-Choice findings from Indonesia. International Journal of Quantitative Research in Education, 3(3), 179-203. doi.org/10.1504/ijqre.2016.077802

Takšić, V. (2002). Emotional competence (intelligence) questionnaires. In: K. LackovićGrgin, A. Bautović, V. Ćubela, \& Z. Penezić (Eds.), The collection of psychological scales and questionnaires (27-45). Zadar, Croatia: University of Zadar.

Tomšik, R., \& Gatial, V. (2018). Choosing teaching as a profession: Influence of big five personality traits on fallback career. Problems of Education in the $21^{\text {st }}$ Century, 76(1), 100-108. doi.org/10.33225/pec/18.76.100

Urquijo, I., Extremera, N., \& Azanza, G. (2019). The contribution of emotional intelligence to career success: Beyond personality traits. Journal of Environmental Research and Public Health, 16(23), 4809. doi.org/10.3390/ijerph16234809

Vesely, A. K., Saklofske, D. H., \& Leschied, A. D. W. (2013). Teachers - The vital resource: The contribution of emotional intelligence to teacher efficacy and wellbeing. Canadian Journal of School Psychology, 28(1), 71-89. doi.org/10.1177/0829573512468855

Vignjević Korotaj, B., \& Mrnjaus, K. (2020). Emotional competence: A prerequisite for effective teaching. Economic research - Ekonomska Istraživanja, 33, 1-14. doi.org/10.1080/1331677x.2020.1751673

Watt, H. M. G., \& Richardson, P. W. (2007). Motivational factors influencing teaching as a career choice: Development and validation of the FIT-Choice Scale. Journal of Experimental Education, 75, 167-202. doi.org/10.3200/jexe.75.3.167-202

Watt, H. M. G., \& Richardson, P. W. (2012). An introduction to teaching motivations in different countries: Comparison using the FIT-Choice scale. Asia-Pacific Journal of Teacher Education, 40(3), 185-197. doi.org/10.1080/1359866x.2012.700049

Watt, H. M. G., Richardson, P. W., \& Devos, C. (2012). (How) Does gender matter in a choice of a STEM teaching career and later teaching behaviours? International Journal of Gender, Science and Technology, 5(3), 187-206. Retrieved from: http://genderandset.open.ac.uk/index.php/genderandset/article/view/331/5 7

Watt, H. M. G., Richardson, P. W., \& Morris, Z. A. (2017). Divided by discipline? Contrasting motivations, perceptions, and background characteristics of beginning English and Mathematics teachers. In H. M. G. Watt, P. W. Richardson \& K. Smith (Eds.), Global perspectives on teacher motivation (pp. 349- 
376). Cambridge, UK: Cambridge University Press. doi.org/10.1017/9781316225202.012

Watt, H. M. G., Richardson, P. W., \& Smith, K. (2017). Why teach? How teachers' motivation matter around the world. In H. M. G. Watt, P. W. Richardson \& K. Smith (Eds.), Global perspectives on teacher motivation (pp. 1-21). Cambridge, UK: Cambridge University Press. doi.org/10.1017/9781316225202.001

Wyatt-Smith, C., Du Plessis, A., Hand, K., Wang, J., Alexander, C., \& Colbert, P. (2017). Why choose teaching? A matter of choice: Evidence from the field. A report prepared for the Queensland College of Teachers. Brisbane, Queensland: Learning Sciences Institute Australia. Retrieved from: https://cdn.qct.edu.au/pdf/WhyChooseTeachingReport.pdf 